\title{
Staphylococcal epidemiology in Antarctica
}

\author{
BY A. S. CAMERON \\ Medical Officer, Australian National Antarctic Research \\ Expeditions, Mawson, 1965-1966*
}

\section{SUMMARY}

An investigation of staphylococcal epidemiology was undertaken at an Australian National Antarctic Research Expedition station during 1965-1966. It concerned the carriage of staphylococci by the men and their dogs, and the occurrence of staphylococci in the station environment. The year-long study indicated that coagulase-negative strains survived better in the Antarctic environment than coagulase-positive strains. It was demonstrated that naturally acquired coagulase-positive strains could not maintain colonization on forearm skin under the usual cold exposure experienced at Mawson station, though coagulasenegative skin strains appeared to thrive during the winter. Staphylococcus albus and $S$. aureus were able to persist in the anterior nares, despite the sometimes lower temperatures recorded in this micro-climate, probably because of the greater humidity and denser populations found there. The majority of the nasal carriers of $S$. aureus were persistent carriers, only two men in 27 being found to be occasional carriers of nasal strains, which was consistent with the observation that transfer of this pathogen from man to man is not common under Antarctic conditions. Half of the 27 sledge dogs at the station were found to carry coagulasepositive staphylococci but this did not appear to be of pathological significance to their human handlers. The local inanimate environment, including mess hut, sleeping huts and sleeping bags used on expeditions, was searched for contamination by $S$. aureus but none was detected.

\section{INTRODUCTION}

A study in staphylococcal epidemiology was undertaken at the Australian National Antarctic Research Expedition (ANARE) station, Mawson, during 1965 concurrently with a previously reported virology programme (Cameron \& Moore, 1968). Changes in the staphylococcal carrier rate have been noted in men who move to a cold climate. McLean (1919) found that Staphylococcus aureus (identified by morphology and colony colour) was not carried in the upper respiratory tract of his subjects after 3 months of exposure to Antarctic conditions; nor did it reappear over the following 6 months of continual cold weather. He noted that $S$. aureus was not recovered from the dust in the living hut though he recorded an increase in the numbers of $S$. albus, bacilli and moulds.

Christie (1958) studied the nasopharyngeal and forearm flora of a small party on expedition in Greenland for three months. Bacterial strains were again identified

* Correspondence to be addressed to Dr A. S. Cameron, c/o Virus Division, Institute of Medical and Veterinary Science, Frome Road, Adelaide, South Australia 5000. 
by microscopic appearance and colonial features. Christie found a decrease in $S$. aureus carriage in the naso-pharynx and perhaps on the skin, while the $S$. albus isolation rate was unaltered.

Sladen (1965) furthered this work on nasal carriage of staphylococci but found that $S$. aureus and $S$. albus persisted in the noses of men in his Antarctic study groups, though he noted that the numbers of intermittent and occasional carriers of S. aureus decreased. Sladen's identification of staphylococcal strains was aided by coagulase testing and phage typing. Few examples of transfer of strains from man to man were detected though there appeared to be ample opportunity for it to occur.

Conditions of cold climate living are difficult to reproduce in temperate climates but Hicks, Poe \& Dooley (1964) report a study using a small group of volunteers engaged in acclimatization experiments in a cold chamber. A tendency for an increase in the rate of carriage of $S$. aureus was noted and some previous noncarriers or intermittent carriers became persistent carriers during the cold phase of the experiment, which lasted 6 weeks.

Hare \& Thomas (1956) demonstrated that staphylococci were spread from the anterior nares of a carrier to his skin and clothing and thence to the surroundings; therefore the methods used in the present study included repeated nose and skin swabbing, air sampling in huts and monitoring of sleeping bags used on sledging expeditions. Nose swabs were also collected from the sledge dogs at the station, for some men had repeated close contact with them and dogs have been shown capable of carrying pathogenic human staphylococci (Pagano et al. 1960; Live \& Nichols, 1961, 1965).

\section{METHODS AND MATERIALS}

\section{The subjects and their environment}

The party under study consisted of 27 healthy Caucasian men. They arrived by sea at Mawson station (Latitude, $67^{\circ} 36^{\prime} \mathrm{S}$; Longitude, $62^{\circ} 53^{\prime} \mathrm{E}$ ) in January 1965. This party occupied the station for 13 months before returning to Australia in March 1966. The only visitors during their sojourn were 11 Russian airmen who stayed at the station for one day just before the final relief.

The climate at Mawson is relatively mild compared with inland stations in Antarctica. The mean air temperature during 1965 was $+10 \cdot 1^{\circ} \mathrm{F}$. with extremes of $-30 \cdot 2^{\circ} \mathrm{F}$. and $+47 \cdot 8^{\circ} \mathrm{F}$. The annual mean wind speed was $20 \cdot 1$ miles per hour and a maximum gust of 134 miles per hour was recorded. Drifting snow was noted on 106 days, usually accompanied by gale-force winds. The relative humidity averaged $59 \%$ but dropped to between 20 and $30 \%$ inside the sleeping huts and $15 \%$ in most of the work huts. The huts were heated by bricquette or oil stoves which kept inside temperatures around $65^{\circ} \mathrm{F}$. throughout the year. All but two of the station buildings were separated from each other, thus all men necessarily experienced some cold exposure during the normal routine of station life (Budd, 1964). Cold exposure was increased considerably on the frequent sledging and tractor-train expeditions mounted to adjacent coastal and inland features. All members of the party were engaged in some field work during the year. 


\section{Collection techniques}

(i) An area approximately $1.5 \mathrm{~cm}$. square was sampled half-way along the midline of the anterior aspect of the forearm. A cotton-tipped applicator stick moistened with sterile nutrient broth was firmly rubbed and rotated over this area for 30 strokes. This site was used in preference to the dorsum of the wrist, a site used in previous surveys of skin flora; for rhinorrhoea is common in the cold and it is tempting for a man to brush his nose with the back of his hand.

(ii) Both anterior nares were sampled using a similar moistened swab.

(iii) When throat swabs were taken for the virus survey, duplicate swabs were obtained for bacteriology. They were immediately streaked on blood agar plates for identification of potential pathogens.

(iv) Air sampling in the mess, recreation room, surgery and sleeping huts was undertaken using Millipore field monitors (MHBG 037 00). Air was sampled at the rate of $10 \mathrm{l} . / \mathrm{min}$. at sites which gave representative samples of the circulating air in the huts, both when occupied and when vacant.

(v) Sleeping bags were sampled following the return of expeditions from the field. Satisfactory samples of the bacterial flora of these bags were obtained by swabbing several sites on each bag with cotton-tipped applicator sticks moistened with saline.

(vi) Techniques for collection and processing of nasal swabs from the dogs were the same in principle as those used for the human nasal swabs. In practice, however, the collection of these samples proved more difficult.

\section{Laboratory procedures}

Mannitol salt agar (MSA; Oxoid CM 86) was used for the primary isolation of staphylococci from the swabs and Millipore filters. Representative colonies were replated on nutrient agar plates (Oxoid CM178) and morphology was checked by

\section{Table 1. Basic set of international phages}

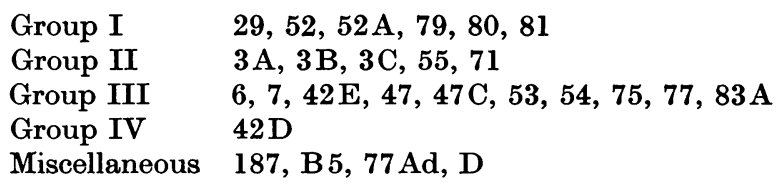

Table 2. Phages used by N.E. Nairn

$\begin{array}{ll}E x \text { Davidson's bovine strains } & 101,102,107 \\ E x \text { Frost's bovine strains } & 367,425,600,13 \\ E x \text { Nairn's bovine strains } & 36,95,140,149,164 \\ E x \text { international set } & 29,80,71,31 \mathrm{~B}, 42 \mathrm{D}, 6,53,77\end{array}$

microscopic examination of Gram-stained smears. Second passage colonies were emulsified in normal saline and the slide coagulase test (Williams \& Harper,1946) was performed at the station. Representative strains were stab-inoculated into nutrient agar, incubated at $37 \cdot 5^{\circ} \mathrm{C}$. for $14 \mathrm{hr}$ and stored at $10^{\circ} \mathrm{C}$., later to be transported to the Institute of Medical and Veterinary Science (IMVS), Adelaide. 
Here the slide coagulase test was repeated and, if necessary, the tube coagulase test was also performed (Fisk, 1940). All specimens were tested for sensitivity to a standard range of antibiotics, and phage typing (Blair \& Williams, 1961), using phages from the International Set, was done on all coagulase-positive specimens. Phages were used at RTD and 1000 RTD and are listed in Table 1.

Canine strains were tested with the human phages, and then sent to Dr N. E. Nairn, Veterinary Pathologist, Department of Agriculture, Government of Western Australia, who retested them with 12 bovine phages at RTD and a selection from the International Set (Table 2).

\section{RESULTS}

\section{Human staphylococci}

Forearm skin

Staphylococci were isolated from all subjects during the year, but were obtained consistently from only 10 men. The majority of forearm skin strains were mannitol negative.

Table 3. Monthly carriage rates for skin and nasal staphylococci

\begin{tabular}{|c|c|c|c|c|c|}
\hline \multirow[b]{3}{*}{ Date } & \multirow[b]{3}{*}{$\begin{array}{l}\text { No. of } \\
\text { subjects }\end{array}$} & \multicolumn{4}{|c|}{ Number carrying } \\
\hline & & \multicolumn{2}{|c|}{ On skin } & \multicolumn{2}{|c|}{ In nose } \\
\hline & & $\begin{array}{l}\text { Staphylo- } \\
\text { cocci }\end{array}$ & $\begin{array}{c}S . \\
\text { aureus }\end{array}$ & $\begin{array}{l}\text { Staphylo- } \\
\text { cocci }\end{array}$ & $\begin{array}{c}S . \\
\text { aureus }\end{array}$ \\
\hline 8. iii. 65 & 27 & 6 & 3 & 21 & 10 \\
\hline 1. iv. 65 & 27 & 10 & 1 & 24 & 10 \\
\hline 19. iv. 65 & 27 & 15 & 0 & 27 & 13 \\
\hline 11. v. 65 & 27 & 12 & 0 & 27 & 12 \\
\hline 9. vi. 65 & 27 & 11 & 0 & 27 & 13 \\
\hline 25. vi. 65 & 27 & 12 & 0 & 27 & 13 \\
\hline 20. vii. 65 & 27 & 11 & 0 & 27 & 13 \\
\hline 24. viii. 65 & 23 & 9 & 0 & 23 & 11 \\
\hline $5 . x .65$ & 27 & 10 & 0 & 27 & 13 \\
\hline 17. xi. 65 & 18 & 4 & 0 & 17 & 10 \\
\hline 20. xii. 65 & 18 & 6 & 1 & 18 & 10 \\
\hline 26. i. 66 & 27 & 7 & 2 & 27 & 12 \\
\hline
\end{tabular}

Swabs from the axillae of six men in February 1966 revealed a scanty population, similar to the forearms, though their groin folds supported a denser population. Two of the subjects yielded a heavy growth of mannitol-positive coagulasenegative staphylococci from the groin swabs similar to the organisms commonly isolated from the bedding and from the air in the sleeping huts.

Only five of the 1965 party carried detectable numbers of coagulase-positive staphylococci at the forearm site during the 14 months of testing (Fig. 1). Five of these eight isolations were obtained between January and April 1965. Then followed a period when repeated testing failed to detect $S$. aureus on the forearm skin. Suddenly, three further isolations were made in December 1965 and January 
1966-all from men who were persistent nasal carriers of $S$. aureus. The penicillin sensitivity and phage type of each subject's skin and nose strains correlated well.

\section{Anterior nares}

In March 1965 staphylococci were isolated from $75 \%$ of the subjects, but by April $1965100 \%$ of them harboured these bacteria and this state remained constant for the rest of the study period (Table 3). Approximately half of these subjects carried mannitol-positive as well as mannitol-negative strains and, in many cases, the former predominated. All the mannitol-positive strains were coagulase-positive, while one man (subject 21) persistently carried a mannitolnegative coagulase-positive strain.

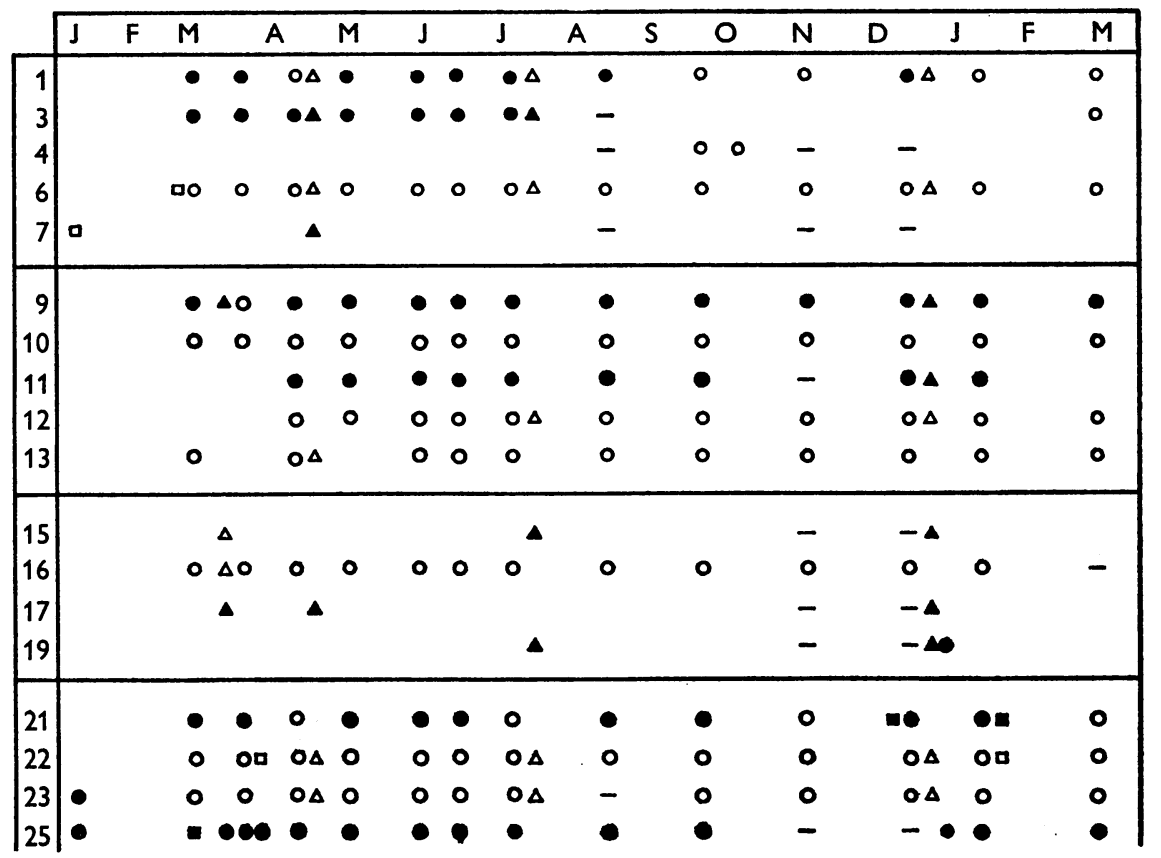

Fig. 1. Schematic representation of the carriage of $S$. aureus. $\bigcirc$, Nasal carrier; $\square$, skin carrier; $\Delta$, oropharyngeal carrier. The blocked-in symbols represent penicillin-resistant strains.

In all, 15 men carried $S$. aureus in their anterior nares at some time during the study period (Fig. 1). Only two of these were occasional carriers. The first (subject 4) carried a coagulase-positive strain for 2 weeks following his return from a long dogsledge trip. His strain was closely related to that carried by subject 3 , who also went on the trip and who ceased to carry the strain (Group I and III) forthwith. The second occasional carrier was subject 19, who held a penicillin-resistant strain, type 80, for a short period following his return from the spring tractor trip. Subjects 17 and 25, other members of this party, carried similar strains. Subject 3 could be classed as an intermittent carrier, losing his nasal strain for at least 5 months and resuming with a different organism. Though some men (subjects 11, 
12 and 16) did not carry their nasal strains for the complete study period, their pattern of constant carriage of organisms of similar phage type for over 9 months allows their inclusion in the category of persistent carriers (Gould \& McKillop, 1954). The remaining nasal carriers were persistent carriers of $S$. aureus with similar phage types at each collection, except subject 13, who changed from type 52 to type 6 during June, and who carried the latter strain for the rest of the year. Six of the 13 long term carriers of $S$. aureus had penicillin-resistant strains.

\section{Oropharynx}

The isolation of staphylococci from throat swabs, though not performed regularly, allowed a pattern of carriage to be determined (Fig. 1). Fourteen men carried coagulase-positive staphylococci on at least one occasion between March 1965 and January 1966. Ten of these were found to be carriers on more than one occasion. Nine of the 14 throat carriers were also persistent nasal carriers of $S$. aureus, while subject 3 ceased carrying his oropharyngeal strain when he lost his comparable nasal strain. Of the 11 men who carried nose and throat strains concurrently, the phage types were comparable in all but four cases. Seven subjects carried penicillin-sensitive strains and six carried penicillin-resistant strains. Subject 15 changed from a penicillin-sensitive type 80,6/47/53/83 A, $187 \mathrm{~B} 5$, to a penicillin-resistant type $53 w$ and later to a type 53 strain resistant to penicillin, tetracycline and erythromycin. The latter was the only strain detected with a similar resistance pattern and this man had not been in contact with any of these antibiotics while in Antarctica.

Phage types of staphylococci, Mawson 1965-1966

The individual phage types will not be detailed, but Table 4 summarizes the frequencies of phage groups isolated from the 1965 party.

Table 4. Phage groups of staphylococci, Mawson, 1965-1966

\begin{tabular}{|c|c|c|c|}
\hline \multirow[b]{2}{*}{ Group } & \multicolumn{3}{|c|}{ Number of strains from } \\
\hline & Skin & $\begin{array}{l}\text { Anterior } \\
\text { nares }\end{array}$ & Oropharynx \\
\hline I & 3 & 12 & 4 \\
\hline $\begin{array}{l}\text { I and III; and I, III } \\
\text { and Miscellaneous }\end{array}$ & $\mathbf{0}$ & 5 & 4 \\
\hline I, II and III & 1 & 0 & 0 \\
\hline III & 0 & 2 & 1 \\
\hline Miscellaneous & 0 & 0 & 1 \\
\hline Non-typable & 1 & 0 & $\mathbf{0}$ \\
\hline
\end{tabular}

\section{Airborne staphylococci}

Staphylococci in the environment

Air volumes of $10 \mathrm{ft}^{3}$ in the mess hut and recreation room were collected during and after periods of occupation but relatively insignificant numbers of bacteria were isolated (numbers of colonies ranged from 1 to 23) and all were coagulase negative strains. Air volumes of $20 \mathrm{ft}^{3}{ }^{3}$ were sampled in the sleeping huts. Again 
very low counts ( 1 to 2 colonies) were found during quiet conditions. Counts rose to about 40 when there was a minor disturbance, when, for instance, one man climbed into bed. With a lot of disturbance of bedding and clothing the counts rose to around 500. By collecting air samples for consecutive half-hour periods it was found that significant numbers of bacteria remained circulating in the hut atmosphere for at least $30 \mathrm{~min}$., then dropped rapidly to insignificance. The major cause of the decrease in bacterial load would be settling of bacteria-carrying particles as dust. Some of the loss is also attributable to air exchange, for one volume of hut air was sucked out as draught through the stove flue every $2 \mathrm{hr}$. under average wind conditions. No coagulase-positive staphylococci were isolated from air samples collected in the buildings.

\section{Canine staphylococci}

Twenty-seven sledge dogs, both adults and pups, were investigated. Seventeen were found to carry staphylococci in the anterior nares and thirteen of the strains were coagulase-positive. The cells were larger than the human strains and were sensitive to all antibiotics tested. No lytic reactions were noted when these canine strains were tested with bovine phages at RTD but seven gave a weak lytic reaction with phage $47 \mathrm{C}$.

\section{DISCUSSION}

This study demonstrated that living under Antarctic conditions may affect the carriage of coagulase-negative staphylococci on the forearm skin. In fact, the carriage rate tended to increase with the onset of colder weather. A more striking seasonal effect was noted on the coagulase-positive skin strains which were isolated only during the summer months, when the skin carrier rate was similar to that in temperate climates (Gillespie, Devenish \& Cowan, 1939; Marples, 1965). Thus a definite ecological advantage was found to exist, favouring the survival of nonpathogenic over pathogenic staphylococci on the skin during the Antarctic winter. The seasonal nature of this change implies that temperature is an important factor in these host-parasite relationships. The bacterial flora of the forearm was exposed to relatively low environmental temperatures, even though the arm was clothed (Winslow \& Herrington, 1949). Doctor J. Hudson (Medical Officer, Mawson 19661967) did a series of skin temperature readings on men in appropriate dress, exposed to routine work conditions, and found that forearm skin temperatures ranged on the average from $31.7^{\circ} \mathrm{C}$. when in the mess, down to $18.2^{\circ} \mathrm{C}$. when doing work in the field. Nasal temperatures under these conditions were $33 \cdot 1^{\circ}$ and $14 \cdot 5^{\circ} \mathrm{C}$. respectively. Note that the nasal temperatures actually fell lower than the skin temperatures and that the present study showed that both pathogenic and non-pathogenic staphylococci thrive in the nose. There are, however, two other factors that should be considered:

(1) The dense colonization of the anterior nares, which would permit rapid regeneration of the population if it was depleted during periods of extreme cold exposure.

(2) The flora of the anterior nares had a much more humid environment than the 
flora of the forearm skin because rhinorrhoea was common during cold exposure. The results of this survey are consistent with the data recorded by Mayyasi, Birkland \& Dodd (1955), who found humidity to be an important factor in the survival of Gram-positive bacteria in the nasal passages of mice, and that of Blank \& Dawes (1958), who also established that desiccation decreased the survival rates of skin bacteria, though they failed to show that only altering the relative humidity favoured the survival of non-pathogens over pathogens.

The number of isolations of oropharyngeal coagulase-positive staphylococci tended to increase during the year, for it was perhaps a more favourable situation than the anterior nares, being humid and probably not as cold.

The number of nasal carriers of $S$. aureus in this group is comparable with the carriage rate for normal populations in temperate zones, but is a little higher than Sladen (1965) found in his Hope Bay, Signy Island, Wilkes and Hallett groups. The Mawson results tend to confirm Sladen's proposal that there is a low incidence of occasional carriers in Antarctica, compared with temperate climates, when from $40 \%$ (Gould \& McKillop, 1954) to 60\% (Hutchinson, Green \& Grimson, 1957) of a normal population will be found to carry staphylococci for short periods if observed over several months. The relative protective effect of an established coagulase-negative population in the anterior nares (Shinefield, Ribble, Boris \& Eichenwald, 1963) may have been a factor preventing the appearance of occasional carriers, for it was noted that the coagulase-negative carrier rate in the Mawson party quickly rose to $100 \%$.

The range of phage types isolated from the 1965 party is peculiar to that population, having a high percentage of group I strains, a few group III and a small proportion of strains difficult to classify satisfactorily. There were no group II isolates, but this is not a polar phenomenon because Sladen records several group II strains and more group III than group I isolations.

McLean (1919) demonstrated that if men stayed in a cold environment for a sufficient length of time they ceased to carry $S$. aureus in their noses and throats. His expedition did not have an effectively heated hut and, within 3 months, no 'golden staphylococci' could be isolated. This was the same stage at which the coagulase-positive skin strains disappeared from the 1965 party. McLean found that $S$. albus could persist where $S$. aureus could not, and this is confirmed by later studies. In contrast, the studies on modern expeditions indicate that nasal and throat carriers continue to hold $S$. aureus, apparently because their cold exposure is neither as great nor as constant as that experienced on Mawson's 1911-14 expedition. It is perhaps significant that subject 3 had been a constant carrier of $S$. aureus in his nose and throat until leaving on a long winter dog-sledge trip. This involved continuous exposure to cold, with long periods of heavy breathing while running with the dogs and sleeping at night in an unheated tent in which temperatures dropped to near ambient (down to $-28^{\circ} \mathrm{C}$.). Subject 23 was the only other persistent carrier of $S$. aureus on this trip, and he retained his type 52 strain. It was on this trip that one instance of transfer of a coagulasepositive strain to an occasional carrier (subject 4) was noted, but colonization was precarious and the coagulase-negative population remained large. It is important 
to note that the transferred strain came from subject 3 and that he and subject 4 lived in adjacent cubicles in the same sleeping hut for the whole of the year, yet no similar transfer was noted to have occurred under station conditions. Another long field trip revealed a second occasional carrier (subject 19). He also lived in the same hut with a possible donor (subject 17) for the year at Mawson. Sladen's subjects O.B. and J.O. perhaps demonstrate this same phenomenon.

Sladen also records that some transfer of pathogenic strains to occasional carriers was noted at Hope Bay and Signy Island. Only two instances of $S$. aureus transfer were noted at Mawson station, and involved subjects 11 and 12, who both continued as persistent carriers from April 1965. This may be analagous to the report by Hicks et al. (1964), that some occasional carriers become persistent carriers when living in a cold environment. Subjects 11 and 12 were hut-mates and the latter apparently became colonized with the nasal strain from subject 13, another occupant of the same hut. The source of subject 11's strain is more obscure, for it was difficult to classify satisfactorily, being group I and III, a relatively common pattern at the station.

The studies of the inanimate environment revealed that no significant contamination by $S$. aureus occurs in the sleeping huts or on the sleeping bags, though S. albus was found in both situations. Transfer of S. albus may well have occurred through the agency of blankets (Rountree \& Beard, 1962) and sleeping bags, but the transfer of $S$. aureus may have to be explained by aerial spread from nose and throat.

The sledge dogs were unexpectedly found to have a high rate of carriage of coagulase-positive staphylococci compared with dogs in temperate regions, for Rountree, Freeman \& Johnson (1956), Pagano et al. (1960) and Smith (1961) found these strains in only $10-15 \%$ of animals tested. Smith (1961) noted a high incidence of coagulase-negative strains in his animals, but they were detected in only three animals in this Antarctic series. It is considered that these Antarctic dogs and their nasal flora represent a unique and specialized ecosystem with little pathological significance for their human handlers.

I wish to acknowledge the assistance and encouragement of the late $\mathrm{Dr} \mathrm{Z}$. Soucek, Medical Officer, Antarctic Division; Dr K. F. Anderson, Head of Bacteriology Division, Institute of Medical and Veterinary Science, and his staff for help with planning the study and with laboratory procedures; and the personnel of the expedition for their willing co-operation. I thank the Acting Director of the Antarctic Division, Department of Supply, and the Director of the Institute of Medical and Veterinary Science for permission to publish the paper.

\section{REFERENCES}

Blatr, J. E. \& Williams, R. E. O. (1961). Phage typing of staphylococci. Bulletin of the World Health Organization 24, 771.

Blank, I. H. \& Dawes, R. K. (1958). The water content of the Stratum corneum. IV. The importance of water in promoting bacterial multiplication on cornified epithelium. Journal of Investigative Dermatology 31, 141. 
BuDD, G. M. (1964). General acclimatization to cold in men studied before during and after a year in Antarctica. ANARE Reports, No. 70, Australian National Antarctic Research Expeditions, Melbourne.

Cameron, A. S. \& Moore, B. W. (1968). The epidemiology of respiratory infection in an isolated Antarctic community. Journal of Hygiene 66, 427.

Christie, R. W. (1958). Bacterial variations in the nasopharynx and skin of isolated arctic scientists. New England Journal of Medicine 258 (ii), 531.

FIsk, A. (1940). The technique of the coagulase test for staphylococci. British Journal of Experimental Pathology 21, 311.

Gillespie, E. H., Devenish, E. A. \& Cowan, S. T. (1939). Pathogenic staphylococci-their incidence in the nose and on the skin. Lancet ii, 870 .

Gould, J. C. \& MCKILlop, E. J. (1954). The carriage of Staphylococcus pyogenes var. aureus in the human nose. Journal of Hygiene 52, 304.

Hare, R. \& Thomas, C. G. A. (1956). The transmission of Staphylococcus aureus. British Medical Journal ii, 840.

Hicks, C. C., Poe, R. H. \& Dooley, E. S. (1964). The nasal and skin carriage of Staphylococcus aureus in an artificial cold environment. Military Medicine 129 (i), 264.

Hutchinson, J. G. P., Green, C. A. \& Grimson, T. A. (1957). Nasal carriage of Staphylococcus aureus in nurses. Journal of Clinical Pathology 10, 92.

Live, I. \& Nichols, A. C. (1961). The animal hospital as a source of antibiotic resistant staphylococci. Journal of Infectious Diseases 108, 195.

Live, I. \& Nichols, A. C. (1965). Serologic typing of staphylococci as an aid in epidemiological studies. Journal of Infectious Diseases 115, 197.

McLean, A. L. (1919). Bacteriological and other researches. In Australasian Antarctic Expedition, 1911-14, Scientific Reports, Series C, VII (4), Sydney.

MARPLES, M. J. (1965). The Ecology of the Human Skin, p. 578. Springfield: Thomas.

MAYYASI, S. A., BirkLAND, J. M. \& DodD, M. C. (1955). Effect of temperature and humidity on nasal flora of mice. Proceedings of the Society for Experimental Biology and Medicine 90, 446.

Pagano, J. S., Farrer, S. M., Plotkin, S. A., Brackman, P. S., Fekety, F. R. \& Pidcoe, V. (1960). Isolation from animals of human strains of staphylococci during an epidemic in a veterinary school. Science $131,927$.

Rountree, P. M. \& BeARD, M. A. (1962). Observations on the distribution of Staphylococcus aureus in the atmosphere of a surgical ward. Journal of Hygiene 60, 387.

Rountree, P. M., Freeman, B. M. \& Johnston, K. G. (1956). Nasal carriage of Staphylococcus aureus by various domestic and laboratory animals. Journal of Pathology and Bacteriology 72, 319.

Shinefield, H. R., Ribble, J. C., Boris, M. \& Eichenwald, H. F. (1963). Bacterial interference: its effect on nursery-acquired infection with Staphylococcus aureus. I. Preliminary observations on artificial colonization of newborns. American Journal of Diseases of Children 105, 646.

SLADEN, W. J. L. (1965). Staphylococci in noses and streptococci in throats of isolated and semi-isolated Antarctic communities. Journal of Hygiene 63, 105.

Sмгтн, J. E. (1961). The aerobic bacteria of the nose and tonsils of healthy dogs. Journal of Comparative Pathology 71, 428.

Williams, R. E. O. \& HARPer, G. J. (1946). Determination of coagulase and alpha-haemolysin production by staphylococci. British Journal of Experimental Pathology 27, 72.

Winslow, C. E. A. \& Herrington, L. P. (1949). Temperature and Human Life, 1st ed. p. 80, Princeton University Press. 